Short Communication

\title{
Investigation of Growth kinetics of the Electrochemical Germanium Nanowire Array Deposition in Galvanostatic Regime Using Indium Nanoparticles
}

\author{
Ilya Gavrilin*, Irina Martynova, Andrei Zakharov and Sergey Gavrilov \\ National Research University of Electronic Technology (MIET), Bld. 1, Shokin Square, 124498, \\ Zelenograd, Moscow, Russian Federation \\ *E-mail: gavrilin.ilya@gmail.com
}

Received: 1 December 2021 / Accepted: 6 January 2022 / Published: 2 February 2022

The features of growth kinetics of the electrochemical Ge nanowires deposition from $\mathrm{GeO}_{2}$ aqueous solutions using indium nanoparticles as crystallization centers are reported. The use of the galvanostatic regime makes it possible to identify sections on the obtained potential-time curves that corresponds to the beginning and completion of the Ge nanowires growth process. It has been established that the $\mathrm{Ge}$ nanowires formation efficiency does not depend on the indium mass deposited on the substrate. However, the increase of current density leads to a decrease of the indium mass which participates in the Ge nanowires formation.

Keywords: Ge nanowires, galvanostatic regime, cathodic deposition, nanoparticles.

\section{$\underline{\text { FULL TEXT }}$}

(C) 2022 The Authors. Published by ESG (www.electrochemsci.org). This article is an open access article distributed under the terms and conditions of the Creative Commons Attribution license (http://creativecommons.org/licenses/by/4.0/). 